\title{
Association of serum and follicular fluid leptin and ghrelin levels with in vitro fertilization success
}

\author{
Suleyman Akarsu' ${ }^{1}$, Barıs Buke ${ }^{2}$, Funda Göde ${ }^{1}$, Kerem Enver Dirican ${ }^{3}$, \\ Alper Başbuğ ${ }^{4}$, Seyit Temel Ceyhan ${ }^{5}$, Umit Goktolga ${ }^{6}$, Okan Akın7, \\ Cem Korkmaz ${ }^{5}$, Cengiz Kara7 , Ahmet Zeki Isık ${ }^{1}$ \\ ${ }^{1}$ Medical Park Hospital, IVF center, Izmir, Turkey \\ 2Irenbe IVF center, Izmır, Turkey \\ ${ }^{3}$ Akdeniz University, IVF center, Antalya, Turkey \\ ${ }^{4}$ Düzce University, Faculty of Medicine, Duzce, Turkey \\ ${ }^{5}$ Gülhane Education and Training Hospital, Ankara, Turkey \\ ${ }^{6}$ Bahceci IVF Clinic, Istanbul, Turkey \\ ${ }^{7}$ Medical Park Hospital, Ankara, Turkey
}

\begin{abstract}
Objectives: The aim of this study was to evaluate the relationship between in vitro fertilization (IVF) cycle outcomes, serum and follicular fluid (FF) levels of leptin and ghrelin.

Material and methods: Forty-four women who underwent intracytoplasmic sperm injection cycles (ICSI) were enrolled in the study. On the third day (D3) of the menstrual cycle, venous blood samples were drawn for serum measurements of leptin and ghrelin. The follicular fluid (FF) and the corresponding oocyte were obtained from a single dominant preovulatory follicle at the time of oocyte pick-up. The FF and D3 serum leptin and ghrelin concentrations were measured by enzyme-linked immunosorbent assay. The relationship between pregnancy rate and serum, follicular fluid levels of leptin and ghrelin were analyzed.

Results: Of the 44 cases included, nineteen achieved clinical pregnancy (43.18\%). Follicular fluid ghrelin levels were significantly lower in the pregnant group than non-pregnant group $(p<0.05)$ With respect to FF leptin, there was no statistically significant differences between the pregnant and non-pregnant women $(p>0.05)$. There was no statistically significant difference in D3 serum ghrelin between pregnant and non-pregnant groups $(p>0.05)$. However, D3 serum leptin levels were significantly lower in pregnant women than non-pregnant women $(p<0.05)$.

Conclusions: Lower ghrelin levels in the follicular fluid were associated with higher pregnancy rates. Also, D3 serum leptin levels were inversely correlated with clinical pregnancy rates. These findings support the potential role of these molecules on IVF outcomes.
\end{abstract}

Key words: ghrelin, leptin, clinical pregnancy, follicular fluid, in vitro fertilization

Ginekologia Polska 2017; 88, 9: 469-474

\section{INTRODUCTION}

The regulation of energy intake and energy expenditure influences reproduction outcomes via a complex hypothalamic neurocircuitry. Nourishment and low body fat downregulate the reproductive axis via circulating factors and hypothalamic circuits [1]. Various adipocytokines are involved in the relation- ship between reproduction and adiposity. Beyond the effect on hypothalamo-pituitary axis, these adipocytokines affect ovarian intrafollicular interactions at multiple levels, including steroidogenesis, metabolic and inflammatory pathways [2].

Leptin is an important peripheral signal that indicates body fat stores to the hypothalamus and acts within the hy- 
pothalamus to limit food intake. Leptin is a $16 \mathrm{kDa}, 146 \mathrm{ami}-$ no acid protein that is secreted from the adipose tissue. The importance of leptin as a signal of fat mass was first demonstrated in mice in 1994 [3]. Interestedly, leptin-deficient mice are infertile and replacement of leptin that exogenously restores fertility and prevents obesity [4]. Subsequently, its absence and related effects on humans were identified. Similar to mice, people treated with exogenous leptin were hyperphagic and hyperinsulinemic [5]. Also, excessive leptin secretion was related to infertility in obese women [6].

In contrast to leptin, ghrelin - a 28 amino acid peptide - acts within the hypothalamus to stimulate food intake [7]. It is predominantly synthesized in the stomach and is an endogenous agonist of the growth hormone secretagogue receptor (GHS-R) [8]. It modulates growth hormone secretion suggesting that ghrelin has a separate role in antagonizing the actions of leptin to promote food intake and weight gain [9]. Ghrelin is effective in GH-deficient rats and increases adiposity in chronic exposure in contrast to $\mathrm{GH}$ [10]. It also stimulates food consumption by increasing the respiratory quotient, reducing fatty acid oxidation and switching to glycolysis for energy expenditure [11]. Ghrelin was also found to suppress the hypothalamic $\mathrm{GnRH}$ release and $\mathrm{GnRH}$-induced gonadotropin secretion by the hypophysis in hypothalamic system in recent reports [12-15]. In a recent study, serum and follicular fluid ghrelin levels correlated negatively with the cleavage rate and number of viable day 3 embryos [15].

Although some other studies have investigated the effect of serum and follicular levels of leptin and ghrelin in infertile women undergoing IVF cycles, their results are conflicting [15-17]. The exact relationship between clinical pregnancy rates and serum/follicular fluid levels of ghrelin and leptin remains unclear. Therefore, our goal was to show how leptin and ghrelin levels in the serum and follicular fluid affect the success of IVF cycles.

\section{MATERIAL AND METHODS}

The study population included 44 women who had undergone intracytoplasmic sperm injection (ICSI) cycles because of unexplained infertility between March 2006 and June 2006 at Gülhane Military Medical Academy (Ankara, Turkey). The study protocol was approved by the local Ethics Committee; informed written consent was obtained from all of the participants prior to controlled hyperstimulation.

All of the patients had regular menstrual cycles and normal ovulatory function as shown by midluteal plasma progesterone and ultrasonographic scanning. They were of the Caucasian race, had normal blood pressure, were non-smoking and not taking any medication, and not involved in intensive exercise. Infertility diagnosis included idiopathic infertility, patients with a concomitant disease such as uter- ine anomaly, fibroids, ovarian cyst or pelvic inflammatory disease were excluded from the study. The long protocol was the method of choice for controlled ovarian hyperstimulation in all cases: $3.75 \mathrm{mg} /$ day of gonadotropin-releasing hormone agonist (Triptorelin)was administrated on day 21 of the menstrual cycle preceding oocyte retrieval. After the attainment of pituitary desensitization, indicated by serum estradiol levels, stimulation was initiated with recombinant FSH (Puregon, Organon, The Netherlands). The daily dose of gonadotrophins was continued on an individual basis, depending upon follicular growth. When the leading follicle reached $18 \mathrm{~mm}$ in diameter $10.000 \mathrm{IU}$ of hCG was administered (Pregnyl, Organon, The Netherlands). 34-36 hours after the hCG injection, oocytes were recovered by transvaginal ultrasound-guided follicle aspiration. After oocyte isolation, the follicular fluid was centrifuged at $3000 \mathrm{xg}$ for $10 \mathrm{~min}$ at $-4^{\circ} \mathrm{C}$ to remove debris, blood and granulosa cells, and was then frozen at $-80^{\circ} \mathrm{C}$ until evaluation. Follicular fluids that were contaminated with significant quantities of blood cells were not used for the analysis. Follicle stimulating hormone $(\mathrm{FSH})$, luteinizing hormone $(\mathrm{LH})$, and estradiol $\left(\mathrm{E}_{2}\right)$ serum levels at the third day of menstrual cycle and the follicular fluid (FF) at the day of oocyte collection were measured.

Fasting blood samples were obtained on the third day of menstruation and on oocyte pick-up (OPU) day. For biochemical examinations, sera were simultaneously separated for ghrelin and leptin assays at $4^{\circ} \mathrm{C}$ immediately after blood sampling. Serum samples were kept frozen at $-20^{\circ} \mathrm{C}$ till biochemical analysis. Leptin concentrations were measured by enzyme-linked immunosorbent assay (ELISA) (DRG Diagnostic International, Inc., USA), and the samples were read with a TRITURUS instrument, (Barcelona, Spain). Within-day and between-day assay coefficients of variation of the leptin were $4.8 \%$ and $8.9 \%$, respectively. The sensitivity of the leptin ELISA kit was $0.2 \mathrm{ng} / \mathrm{mL}$. Total serum ghrelin concentrations were measured using a commercial radioimmunoassay (RIA) that utilizes a ${ }^{125} \mathrm{I}$-labeled ghrelin as a tracer and a rabbit polyclonal antibody raised against full-length octanoylated human ghrelin (Phoenix, Europe, Karlsruhe, Germany).(21) Samples were read with a LKBWallac, MultiGamma ${ }^{126} 1$, Turku 10(Finland). Within-day and between-day assay coefficients of variation of the ghrelin were $2.3 \%$ and $7.9 \%$, respectively. The ghrelin radioimmunoassay (RIA) had a sensitivity of $10 \mathrm{pg} / \mathrm{mL}$. Serum and follicular fluid follicle-stimulating hormone ( $\mathrm{FSH}$; follitropin), luteinizing hormone (LH; lutropin) and estradiol levels were measured with a chemiluminescence method and an automatic analyzer Immulite ${ }^{\circledR} 1000$ (Siemens Healthcare Diagnostics IL, USA).

\section{Statistical analysis}

The SPSS software SPSS 20 (IBM Corp. Released 2011. IBM SPSS Statistics for Windows, Version 20.0. Armonk,NY: IBM 
Table 1. Baseline characteristics of pregnant and non-pregnant patients

\begin{tabular}{|l|c|c|c|}
\hline Variable & Pregnant (n: 19) & Non-pregnant (n: 25) & P value \\
\hline Age (years) & $29.50 \pm 4.18$ & $31.22 \pm 4.17$ & 0.214 \\
\hline BMI [kg/m²] & $24.91 \pm 3.68$ & $25.8 \pm 3.93$ & 0.510 \\
\hline D3 FSH [mlU/mL] & $6.08 \pm 3.74$ & $7.21 \pm 3.87$ & 0.338 \\
\hline D3 LH [mlU/mL] & $7.29 \pm 3.66$ & $8.06 \pm 3.48$ & 0.455 \\
\hline Duration of infertility (years) & $9.38 \pm 4.70$ & $9.18 \pm 3.25$ & 0.881 \\
\hline Number of oocytes & $12.79 \pm 5.64$ & $9.8 \pm 6.03$ & 0.101 \\
\hline OPU E2 [pg/mL] & $3229.25 \pm 1490.57$ & $2725.19 \pm 2045.27$ & 0.432 \\
\hline Number of ET & $2.37 \pm 0.6$ & $2.16 \pm 0.99$ & 0.421 \\
\hline D3 endometrial thickness [mm] & $4.97 \pm 0.44$ & $4.88 \pm 0.32$ & 0.661 \\
\hline OPU day endometrial thickness [mm] & $9.07 \pm 1.12$ & $8.69 \pm 1.22$ & 0.425 \\
\hline Total dose of gonadotropin [IU] & $2178 \pm 456.5$ & $2327.5 \pm 528.6$ & 0.573 \\
\hline
\end{tabular}

\section{Table 2. Comparison of D3, FF, OPU leptin and ghrelin levels in the two groups}

\begin{tabular}{|l|c|c|c|}
\hline Variable & Pregnant (n: 19) & Non pregnant (n: 25) & P value \\
\hline FF FSH [mlU/mL] & $4.61 \pm 2.98$ & $5.75 \pm 3.64$ & 0.273 \\
\hline FF LH [mlU/mL] & $5.66 \pm 2.83$ & $6.65 \pm 4.37$ & 0.273 \\
\hline D3 ghrelin [ng/mL] & $10.2 \pm 5.92$ & $9.15 \pm 3.99$ & 0.488 \\
\hline FF ghrelin [ng/mL] & $79.37 \pm 43.12$ & $145.65 \pm 113.86$ & 0.021 \\
\hline OPU ghrelin [ng/mL] & $10.42 \pm 7.60$ & $9.52 \pm 4.33$ & 0.621 \\
\hline FF leptin [pg/mL] & $922.89 \pm 53.08$ & $885.78 \pm 143.54$ & 0.291 \\
\hline OPU leptin [pg/mL] & $956.89 \pm 50.97$ & $920.47 \pm 85.31$ & 0.107 \\
\hline D3 leptin [pg/mL] & $899.93 \pm 61.79$ & $937.52 \pm 45.18$ & 0.025 \\
\hline
\end{tabular}

Corp) was used for the statistical analysis. The continuous variables were investigated via the Shapiro-Wilkes test in terms of normal distribution. Descriptive statistics were expressed as a mean \pm standard deviation.The significance of the differences between the mean values of the pregnant and non-pregnant groups was evaluated by the Student's t-test in parametric conditions, Mann-Whitney $U$ test in non-parametric conditions. After single-variable statistical analyses, binary logistic regression analysis was performed to evaluate the effects of the clinically significant variables as well as the variables that affect pregnancy rates. If a single variable resulted in a $p<0.25$ value, then this variable was included in the multiple variable analysis as a possible candidate affecting pregnancy rates. The odds ratio and $95 \%$ confidence intervals were evaluated for each variable; $p<0.05$ was considered to be statistically significant.

\section{RESULTS}

19 of the 44 women achieved clinical pregnancy (43.18\%). There were no statistically significant differences between pregnant and non-pregnant women in terms of age, BMI, D3 FSH, D3 LH, duration of infertility, the number of oocytes, OPU E2, the number of embryos transferred (ET),
D3 endometrial thickness, OPU day endometrial thickness and gonadotropin dosage respectively (Table 1).

There were no statistically significant differences between pregnant and non-pregnant groups regarding D3 serum, OPU serum ghrelin levels as well as FF and OPU leptin levels. However, FF ghrelin levels were significantly lower in the pregnant group than non-pregnant group $(79.37 \pm 43.12$ and $145.65 \pm 113.86 \mathrm{ng} / \mathrm{mL}$ respectively $\mathrm{p}<0.05$ ) (Table 2). Also, the mean D3 leptin levels were lower in the pregnant group, and the difference was statistically significant $(899.93 \pm 61.79$ and $937.51 \pm 45.18 \mathrm{pg} / \mathrm{mL}$ respectively, $\mathrm{p}<0.05$ ) (Table 2 ).

To evaluate the relationship between D3 serum, FF leptin, ghrelin values with clinical pregnancies, binary logistic regression analysis was performed. As a result of this analysis, D3 serum leptin levels were found to be negative and independently correlated with clinical pregnancies relative to all other parameters investigated including $\mathrm{BMI}$ and age (OR: 0.956, $p=0.039$ ) (Table 3).

\section{DISCUSSION}

The aim of this prospective cohort study was to evaluate the relationship between the outcome of assisted reproduc- 
Table 3. Odds ratios of the variables as a result of binary logistic regression analysis

\begin{tabular}{|c|c|c|c|c|}
\hline \multirow{2}{*}{ Variable } & \multirow{2}{*}{ Odds ratio } & \multicolumn{2}{|c|}{$95 \%$ confidence interval } & \multirow{2}{*}{ P value } \\
\hline & & Lower & Upper & \\
\hline Age & 2.144 & 0.840 & 5.477 & 0.111 \\
\hline BMI & 0.677 & 0.410 & 1.115 & 0.126 \\
\hline Day3 FSH & 1.606 & 0.540 & 4.782 & 0.395 \\
\hline Day3 LH & 0.985 & 0.530 & 1.829 & 0.961 \\
\hline OPU FSH & 0.345 & 0.086 & 1.384 & 0.133 \\
\hline OPU E2 & 1.002 & 1.000 & 1.004 & 0.103 \\
\hline FF ghrelin & 0.975 & 0.946 & 1.006 & 0.110 \\
\hline FF leptin & 1.016 & 0.997 & 1.036 & 0.098 \\
\hline OPU leptin & 1.042 & 1.002 & 1.085 & 0.055 \\
\hline Day3 leptin & 0.956 & 0.915 & 0.998 & 0.039 \\
\hline D3 endometrial thickness & 1.702 & 1.433 & 2.170 & 0.632 \\
\hline OPU day endometrial thickness & 2.644 & 2.018 & 3.645 & 0.298 \\
\hline
\end{tabular}

tion cycles as a function of leptin and ghrelin levels in FF, D3 serum, and OPU serum. The data suggest that of the parameters investigated, follicular fluid ghrelin levels and D3 serum leptin levels negatively correlated with pregnancy rates regardless of the other parameters (especially BMI and age) the D3 serum leptin levels were lower in the pregnant group, the difference was statistically significant.

Reproduction is a sophisticated function that depends on adequate energy and homeostasis [18]. Several studies have demonstrated the complex relationship between adipocytokines and reproduction as well as between fat reserves and fertility. Leptin and ghrelin are the two key functional antagonists in the control of metabolism and energy homeostasis [19]. Thus, we decided to study serum and FF levels of these two hormones to understand their direct relationship on clinical pregnancy rates. Focusing on FF levels would show their effect on the ovarian environment, but it should be kept in the mind that endometrial implantation and embryonic development are also part of reproduction. Thus, only FF levels would be insufficient to show the reproductive effects of these hormones [20]. Several studies have shown the effect of leptin and ghrelin on endometrial receptivity. Therefore, clinical pregnancy rates would be improved [21-23].

Leptin can act at any level of reproduction from HPG to gametogenesis. It seems to be mandatory for normal reproductive function [24]. However, observations of the positive effects of leptin on oocytes from several animal studies have shown that the definite effect of leptin on reproductive organs remains unknown [24-26]. Most studies show a negative correlation between leptin and IVF outcomes like embryo quality, fertilization and pregnancy rates [16, $17,27]$. Others suggest that there is no correlation [28]. More recently, increased leptin levels have indicated better
IVF outcomes [29]. Thus, the relationship between leptin and reproduction remains vague.

Most studies regarding serum levels of leptin and reproduction assess the increase in leptin levels during ovarian hyperstimulation. Therefore, one might study the effect of hyperstimulation on leptin levels rather than the effect of leptin on IVF outcomes. Similar to our study, Brannian et al., investigated the relationship between reproductive outcomes and baseline (D3) serum leptin levels/BMI. They found that low levels of leptin/BMI were related to high IVF success. They adjusted serum leptin levels, according to BMI [30]. In our data analysis, we adjusted serum leptin levels, according to all parameters including BMI and age similar to Brannian et al. We found a negative correlation between D3 serum leptin levels and clinical pregnancies - this is absolutely the main parameter showing the success of IVF. Our data suggest that D3 serum leptin levels could be a simple tool to predict IVF success after adjustment for other parameters.

The effect of ghrelin on the regulation of the reproductive system has not been equally assessed versus other physiological functions of this peptide hormone [31]. Ghrelin is a metabolic antagonist of leptin and is an indicator of energy insufficiency. It was supposed to have a negative effect on reproductive biology because of its suppressing role in $\mathrm{GnRH}$ [12]. Also, it was suggested that Ghrelin might have an autocrine-paracrine role in the ovary. Thus it was shown that ghrelin exerted an inhibitory effect on granulosa-lutein cells steroidogenesis by acting through its functional receptor GHs-R1a [32]. Ghrelin was also shown to inhibit the development of mouse preimplantation embryos in vitro [33]. Recently Li et al. reported a negative association between follicular fluid ghrelin and embryo development, possibly through interactions with follicular fluid insulin [15]. Our 
data also suggested that there was a negative relationship between follicular fluid ghrelin levels and pregnancy rate. Thus, the definite effect of ghrelin on reproductive function is debated and needs further investigation.

\section{CONCLUSION}

In conclusion, although baseline (D3) serum leptin levels and follicular fluid ghrelin levels might be prognostic tools for IVF outcomes, but our sample size was limited. Thus, we believe that further investigations both regarding the effect of leptin and ghrelin on IVF success should be carried out in the near future on this subject matter.

\section{Decleration of interest}

None.

\section{Conflict of interest}

None.

\section{Acknowledgement}

We thank Mustafa Agah Tekindal for statistical analysis.

\section{REFERENCES}

1. Dondorp W, de Wert G, Pennings G, et al. ESHRE Task Force on Ethics and Law, including. Lifestyle-related factors and access to medically assisted reproduction. Hum Reprod. 2010; 25(3): 578-583, doi: 10.1093/humrep/dep458, indexed in Pubmed: 20085914.

2. Robker RL, Akison LK, Bennett BD, et al. Obese women exhibit differences in ovarian metabolites, hormones, and gene expression compared with moderate-weight women. J Clin Endocrinol Metab. 2009; 94(5): 1533-1540, doi: 10.1210/jc.2008-2648, indexed in Pubmed: 19223519.

3. Zhang Y, Proenca R, Maffei M, et al. Positional cloning of the mouse obese gene and its human homologue. Nature. 1994; 372(6505): 425-432, doi: 10.1038/372425a0, indexed in Pubmed: 7984236.

4. Chehab FF, Lim ME, Lu R. Correction of the sterility defect in homozygous obese female mice by treatment with the human recombinant leptin. Nat Genet. 1996; 12(3): 318-320, doi: 10.1038/ng0396-318, indexed in Pubmed: 8589726

5. Farooqi IS, Jebb SA, Langmack G, et al. Effects of recombinant leptin therapy in a child with congenital leptin deficiency. N Engl J Med. 1999; 341(12): 879-884, doi: 10.1056/NEJM199909163411204, indexed in Pubmed: 10486419.

6. Comninos AN, Jayasena CN, DhilloWS. The relationship between gut and adipose hormones, and reproduction. Hum Reprod Update. 2014; 20(2): 153-174, doi: 10.1093/humupd/dmt033, indexed in Pubmed: 24173881.

7. Small C, Bloom S, Stanley S. Neuropeptide regulation of appetite and reproduction. Journal für Reproduktionsmedizin und Endokrinologie-Journal of Reproductive Medicine and Endocrinology. 2004; 1: 13-19.

8. Kojima M, Hosoda H, Kangawa K, et al. Ghrelin: discovery of the natural endogenous ligand for the growth hormone secretagogue receptor. Trends Endocrinol Metab. 2001; 12(3): 118-122, indexed in Pubmed: 11306336.

9. Wren AM, Small CJ, Ward HL, et al. The novel hypothalamic peptide ghrelin stimulates food intake and growth hormone secretion. Endocrinology. 2000; 141(11): 4325-4328, doi: 10.1210/endo.141.11.7873, indexed in Pubmed: 11089570.

10. Nakazato $M$, Murakami N, Date $Y$, et al. A role for ghrelin in the central regulation of feeding. Nature. 2001; 409(6817): 194-198, doi: 10.1038/35051587, indexed in Pubmed: 11196643.

11. Tschöp M, Smiley DL, Heiman ML. Ghrelin induces adiposity in rodents. Nature. 2000; 407(6806): 908-913, doi: 10.1038/35038090, indexed in Pubmed: 11057670.

12. Vulliémoz $N R$, Xiao $E$, Xia-Zhang $L$, et al. Decrease in luteinizing hormone pulse frequency during a five-hour peripheral ghrelin infusion in the ovariectomized rhesus monkey. J Clin Endocrinol Metab. 2004; 89(11): 5718-5723, doi: 10.1210/jc.2004-1244, indexed in Pubmed: 15531534.

13. Fernández-Fernández $R$, Tena-Sempere $M$, Navarro VM, et al. Effects of ghrelin upon gonadotropin-releasing hormone and gonadotropin secretion in adult female rats: in vivo and in vitro studies. Neuroendocrinology. 2005; 82(5-6): 245-255, doi: 10.1159/000092753, indexed in Pubmed: 16721030.

14. Ogata R, Matsuzaki T, Iwasa T, et al. Hypothalamic Ghrelin suppresses pulsatile secretion of luteinizing hormone via beta-endorphin in ovariectomized rats. Neuroendocrinology. 2009; 90(4): 364-370, doi: 10.1159/000257421, indexed in Pubmed: 19907132.

15. Li L, Ferin M, Sauer MV, et al. Serum and follicular fluid ghrelin levels negatively reflect human oocyte quality and in vitro embryo development. Fertil Steril. 2011;96(5): 1116-1120, doi: 10.1016/j.fertnstert.2011.08.017, indexed in Pubmed: 21924713.

16. Anifandis G, Koutselini E, Stefanidis I, et al. Serum and follicular fluid leptin levels are correlated with human embryo quality. Reproduction. 2005; 130(6): 917-921, doi: 10.1530/rep.1.00705, indexed in Pubmed: 16322551.

17. Gürbüz B, Yalti S, Ficicioglu C, et al. The relation of serum and follicular fluid leptin and ovarian steroid levels in response to induction of ovulation in in vitro fertilization cycles. Eur J Obstet Gynecol Reprod Biol. 2005; 118(2): 214-218, doi: 10.1016/j.ejogrb.2004.04.038, indexed in Pubmed: 15653206.

18. Vázquez MJ, Romero-Ruiz A, Tena-Sempere M. Roles of leptin in reproduction, pregnancy and polycystic ovary syndrome: consensus knowledge and recent developments. Metabolism. 2015; 64(1): 79-91, doi: 10.1016/j.metabol.2014.10.013, indexed in Pubmed: 25467843.

19. Tena-Sempere M. Interaction between energy homeostasis and reproduction: central effects of leptin and ghrelin on the reproductive axis. Hormone and Metabolic Research. 2013; 45(13): 919-927, doi: 10.1055/s-0033-1355399.

20. Takikawa $S$, Iwase A, Goto $M$, et al. Assessment of the predictive value of follicular fluid insulin, leptin and adiponectin in assisted reproductive cycles. Gynecol Endocrinol. 2010; 26(7): 494-499, doi: 10.3109/09513591003632050, indexed in Pubmed: 20170349.

21. Tawadros N, Salamonsen LA, Dimitriadis E, et al. Facilitation of decidualization by locally produced ghrelin in the human endometrium. Mol Hum Reprod. 2007; 13(7): 483-489, doi: 10.1093/molehr/gam029, indexed in Pubmed: 17494105.

22. Aghajanova L, Rumman A, Altmäe $S$, et al. Diminished endometria expression of ghrelin and ghrelin receptor contributes to infertility. Reprod Sci. 2010; 17(9): 823-832, doi: 10.1177/1933719110371683, indexed in Pubmed: 20616368

23. Martin JR, Lieber SB, McGrath J, et al. Maternal ghrelin deficiency compromises reproduction in female progeny through altered uterine developmental programming. Endocrinology. 2011; 152(5): 2060-2066, doi: 10.1210/en.2010-1485, indexed in Pubmed: 21325042.

24. Brannian JD, Hansen KA. Leptin and ovarian folliculogenesis: implications for ovulation induction and ART outcomes. Semin Reprod Med. 2002; 20(2): 103-112, doi: 10.1055/s-2002-32501, indexed in Pubmed: 12087495.

25. Joo JK, Joo BS, Kim SC, et al. Role of leptin in improvement of oocyte quality by regulation of ovarian angiogenesis. Anim Reprod Sci. 2010; 119(3-4): 329-334, doi: 10.1016/j.anireprosci.2010.02.002, indexed in Pubmed: 20197222.

26. Boelhauve M, Sinowatz F, Wolf E, et al. Maturation of bovine oocytes in the presence of leptin improves development and reduces apoptosis of in vitro-produced blastocysts. Biol Reprod. 2005; 73(4): 737-744, doi: 10.1095/biolreprod.105.041103, indexed in Pubmed: 15958729.

27. Asimakopoulos B, Nikolettos N, Papachristou DN, et al. Follicular fluid levels of vascular endothelial growth factor and leptin are associated with pregnancy outcome of normal women participating in intracytoplasmic sperm injection cycles. Physiol Res. 2005; 54(3): 263-270, indexed in Pubmed: 15588162.

28. Asimakopoulos B, Koster F, Felberbaum R, et al. Intrafollicular and circulating concentrations of leptin do not predict the outcome in IVF-ICSI cycles. Reprod Sci. 2009; 16(1): 113-119, doi: 10.1177/1933719108324139, indexed in Pubmed: 19144893.

29. Li L, Ferin M, Sauer MV, et al. Ovarian adipocytokines are associated with early in vitro human embryo development independent of the action of ovarian insulin. J Assist Reprod Genet. 2012; 29(12): 1397-1404, doi: 10.1007/s10815-012-9864-1, indexed in Pubmed: 23054357. 
30. Brannian JD, Schmidt SM, Kreger DO, et al. Baseline non-fasting serum leptin concentration to body mass index ratio is predictive of IVF outcomes. Hum Reprod. 2001; 16(9): 1819-1826, indexed in Pubmed: 11527882.

31. Angelidis G, Dafopoulos K, Messini $\mathrm{Cl}$, et al. Ghrelin: new insights into female reproductive system-associated disorders and pregnancy. Reprod Sci. 2012; 19(9): 903-910, doi: 10.1177/1933719112443880, indexed in Pubmed: 22544849.
32. Viani I, Vottero A, Tassi F, et al. Ghrelin inhibits steroid biosynthesis by cultured granulosa-lutein cells. J Clin Endocrinol Metab. 2008; 93(4): 1476-1481, doi: 10.1210/jc.2007-2063, indexed in Pubmed: 18230661.

33. Kawamura K, Sato N, Fukuda J, et al. Ghrelin inhibits the development of mouse preimplantation embryos in vitro. Endocrinology. 2003; 144(6): 2623-2633, doi: 10.1210/en.2003-0033, indexed in Pubmed: 12746326. 